Int J Infect Microbiol 2012;1(2):58-62

\section{Sero-diagnosis of Dengue virus in different hospitals of Nepal}

\author{
Shah Y,1,2* Khadka G, ${ }^{1}$ Gupta GP, ${ }^{1}$ Adhikari \\ N,1,3 Poudel A, ${ }^{1}$ Pant KP, 4 Dahal B, ${ }^{2}$ Pandey \\ BD $^{1}$
}

${ }^{1}$ Everest International Clinic and Research Center, Kalanki, Kathmandu , Nepal, ${ }^{2}$ Kathmandu College of Science and Technology, Kalimati, Kathmandu, Nepal, ${ }^{3}$ Department of Microbiology, Janaki Medical College, Janakpur Nepal Department of Microbiology, ${ }^{4}$ Siddhanath Science Campus Mahendranagar, Kanchanpur, Nepal

*Correspondence to: Mr. Yogendra Shah, Everest International Clinic and Research Center, Kalanki, Kathmandu, Nepal email: yogendra90@hotmail.co m, Tel. No.: (+977)-9849610127

\begin{abstract}
INTRODUCTION: Dengue fever (DF) is an emerging mosquito borne viral disease and important public health problem in low land Terai region which is also moving towards hilly region Nepal. This study was designed to determine the sero-prevalence of dengue virus infection in patients visiting hospitals of Nepal.
\end{abstract}

MATERIALS AND METHODS: This study was conducted during period (June-November) of 2010 in Nepalese patients with fever visiting hospitals of Birganj, Damouli, Biratanagar, Dhading Besi and Chitwan. The sero-prevalence of dengue virus specific IgM was determined by enzyme linked immunosorbent assay (ELISA). Serum samples were collected from 289 patients visiting hospitals with history of fever and clinically suspected dengue fever.

RESULTS: The anti-dengue IgM positivity was found to be $8.99 \%$. The positive dengue cases were higher in male $(10.8 \%)$ as compared to female $(7.1 \%)$ though it was not statistically significant $(\mathrm{P}>0.05)$. Among different age groups, the highest positive cases $(12.3 \%)$ were from age group below 15 years followed by above 50 years $8.3 \%$. Out of 5 hospitals, the highest positive cases were in Tanahu hospital, Damouli (23.8\%) followed by Bharatpur hospital and Chitwan $(22.2 \%)$. Age and gender were found to be independent predictors. The highest numbers of dengue positive cases were in occupation group business $(13.3 \%)$ followed by agriculture (12.7\%).

CONCLUSIONS: Prevalence of dengue virus infection is increasing and proper control measure should be provided. IgM capture ELISA was used for laboratory analysis and remains as a reliable and inexpensive method for the diagnosis of dengue. Hence, the IgM capture ELISA has become the most accepted technique for the diagnosis of dengue in developing countries like Nepal.

KEY WORDS: Dengue fever, IgM capture, ELISA, Terai region 


\section{INTRODUCTION}

Dengue is an acute febrile illness caused by a virus that is transmitted from human to human via species of Aedes aegypti and Aedes Albopictus mosquitoes. ${ }^{1}$ The incidence of disease has been estimated to be 50-100 million cases per year which is likely to increase due to expanding geographic distribution of both virus and vectors. ${ }^{2}$

Four dengue virus (DV) serotypes viz DEN-1, DEN-2, DEN-3 and DEN-4 are responsible for the disease. The viral infection in human causes a spectrum of illness ranging from asymptomatic or mild febrile illness i.e dengue fever, which may evolve to severe disease forms i.e dengue hemorrhagic fever (DHF) and dengue shock syndrome (DSS). Secondary dengue virus infection (DVI) has been mainly associated with the severe form of the disease. ${ }^{3}$

Nepal being bordered by India in the eastern, western and southern belts, DF/DHF has been considered to be a possible public health threat. As with other vector borne diseases, outbreak of DF is related with increasing temperature, travel and frequent movement of people which is common due to open border between Nepal and India. Nepal reported larger outbreak in 9 districts in 2006.4,5 The outbreak occurred in Nepal following the Indian, Pakistan and Bhutan epidemic of DF/DHF in September-October 2006.5 DF was first reported in foreign visitor in Chitwan in 2004.6 DF is the emerging disease affecting Nepal since 2004 although DF has been already observed in foreign visitor earlier. 7,8 Nepal reported indigenous transmission of dengue cases in November 2006. ${ }^{9}$ The outbreak occurred in Nepal following the Indian epidemic of DF/DHF in September-October 2006.

At present diagnosis and management of dengue and Japanese encephalitis (JE) in Nepal is based on patients clinical symptoms due to lack of diagnostic facility. ${ }^{10}$ The threat of the DVI in Nepal is emerging as the disease caused significant morbidity and mortality in the neighboring country. Though there is high risk of dengue in Nepal, there are only few studies on the sero-prevalence of the disease. Hence, this study has determined the seroprevalence of dengue in patients visiting hospitals of Nepal.

\section{MATERIALS AND METHODS}

The study was designed as a descriptive crosssectional. The study was carried from June to November 2010. Total number of 289 serum sample were collected from Narayani Sub-regional Hospital (NSH), Birgunj ( $n=173)$; Tanahu District Hospital (TDH), Damouli ( $\mathrm{n}=42)$; Koshi Zonal Hospital (KZH), Biratnagar ( $\mathrm{n}=32)$, Bharatpur hospital (BH) Chitwan $(\mathrm{n}=9)$ and Dhading District Hospital (DDH), Dhading Besi $(n=33)$. Serum samples were collected from individuals experiencing a febrile illness clinically consistent with dengue infection, selected according to the inclusion and exclusion criteria. A case was included if there was high fever with clinical symptoms suggestive of dengue infection. ${ }^{4} \mathrm{~A}$ case was excluded, if routine laboratory testing suggested bacterial or any viral infection other than dengue infection or any other disease. ${ }^{4}$ Patients' personal details about the symptoms, age, sex etc. were obtained through a questionnaire method by direct interview. The entire test was done at Everest International Clinic and Research Center (EICRC), Kalanki, Kathmandu.

Sample collection, storage and transport: The serum samples from suspected cases were collected, stored and transported maintaining the reverse cold chain to EICRC. Aliquots for ELISA and RT-PCR were made and stored at $2-8^{\circ} \mathrm{C}$ and $-20^{\circ} \mathrm{C}$ until tested.

Detection of anti-dengue IgM-Capture by ELISA (SD, Bioline, Korea): The required numbers of micro wells were determined for the assay. Immediately $100 \mu \mathrm{l}$ of diluted serum (1:100) was added into wells coated with anti-human IgM. The plate was incubated at $37^{\circ} \mathrm{C}$ for 60 minutes. Then, the plate was washed five times with diluted wash buffer. A mixture of $100 \mu \mathrm{l} \mathrm{Ag}$ and HRP conjugated MAb was added to the wells. Again the plate was incubated at $37^{\circ} \mathrm{C}$ for 60 minutes. The plate was then washed several times with diluted wash buffer. One hundred micro liter of TMB was pipetted and added to each well. Incubation was done at $25-30^{\circ} \mathrm{C}$ for 10 minutes. Finally, $100 \mu \mathrm{l}$ of stop solution was added and observed the change in color pattern. Within 30 minutes, the absorbance of each well was taken at a wave length of $450 \mathrm{~nm}$ with a reference filter of $620 \mathrm{~nm}$ by using ELISA Reader. The test was interpreted either positive or negative on the basis of cut-off value of the sample. The cut-off value was obtained by addition of 0.3 to average absorbance of negative controls. If absorbance of the sample was greater than cut-off value, then it was considered positive and less than cut-off value as negative.

The collected data were analyzed using Statistical Package for Social Science version 16 (SPSS v.16). Chi-square statistics with $\mathrm{p}<0.05$ were considered statistically significant. 
Table 1. Sex Wise Distribution of Positive DV Cases

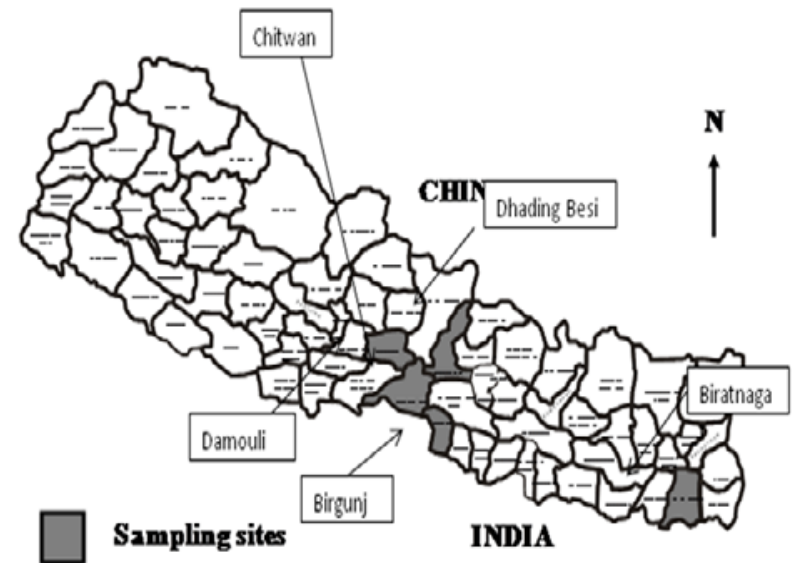

RESULTS

Out of 289 IgM ELISA performed serum samples of dengue suspected cases, $26(9 \%)$ were found to be positive for anti-dengue IgM and 289. Sex wise positive cases for dengue was observed high in male $(10.8 \%)$ which constituted $5.5 \%$ of total cases and low in female $(7.1 \%)$ which comprised $3.25 \%$ of total cases. Statistically, this was significant ( $p$ $=0.04$ ) between male and female for the occurrence of disease (Table 1).

Age wise positive cases of dengue was observed highest in age group below 15 years (12.3\%) which constituted $3.5 \%$ of total cases and least in age group 15-50 years (7.5\%) which comprised $4.5 \%$ of total cases. Statistically, there is no significant relationship $(p=0.24)$ between age groups for the occurrence of disease (Table 2).

Hospital wise positive cases were observed highest in TDH 10 (23.8\%) and least in DDH 1 (3.0\%). Statistically there was significant relationship $(p=0.001)$ between different hospitals for the occurrence of the disease (Table 3).

Occupation wise positive case was observed highest in business group (13.3\%) which constituted $5.2 \%$ of total cases and least in job holder and other groups. Statistically there is no significant relationship ( $p=0.48)$ between occupation group for the occurrence of the disease (Table 4).

\section{DISCUSSION}

The present findings showed that dengue prevalence rate was found to be $9 \%$ by IgM ELISA. The sero-positivity of the study was not in acccorda-

\begin{tabular}{|c|c|c|c|c|}
\hline$\stackrel{\rtimes}{凶}$ & 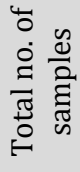 & 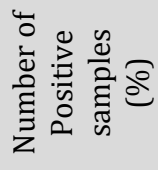 & 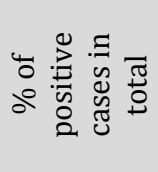 & 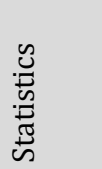 \\
\hline Male & 148 & $16(10.8)$ & 5.5 & \multirow{3}{*}{$\begin{array}{l}\chi^{2}=3.6 \\
p=0.04\end{array}$} \\
\hline $\begin{array}{l}\text { Femal } \\
\text { e }\end{array}$ & 141 & $10(7.1)$ & 3.5 & \\
\hline Total & 289 & $26(9)$ & 9 & \\
\hline
\end{tabular}

Table 2. Age Wise Distribution of Positive DV cases

\begin{tabular}{|c|c|c|c|c|}
\hline 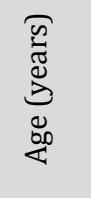 & 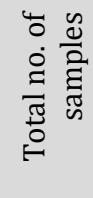 & 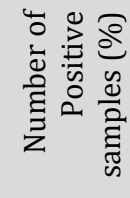 & 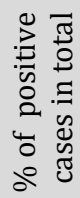 & 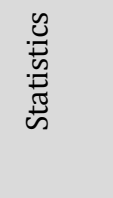 \\
\hline$<15$ & 81 & $10(12.3)$ & 3.5 & \multirow{4}{*}{$\begin{array}{l}\chi^{2}=2.82 \\
p=0.24\end{array}$} \\
\hline $15-50$ & 172 & $13(7.5)$ & 4.5 & \\
\hline$>50$ & 36 & $3(8.3)$ & 1 & \\
\hline Total & 289 & $26(9)$ & & \\
\hline
\end{tabular}

Table 3: Hospital wise distribution of positive DV cases

\begin{tabular}{|c|c|c|c|c|}
\hline 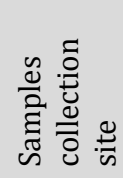 & 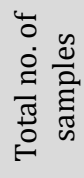 & 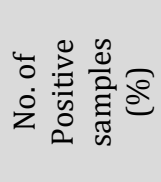 & 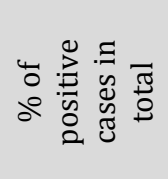 & 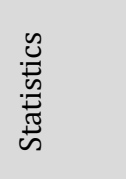 \\
\hline NSH & 173 & $9(5.2)$ & 3.2 & \multirow{6}{*}{$\mathrm{p}=0.001$} \\
\hline KZH & 32 & $4(12.5)$ & 1.4 & \\
\hline TDH & 42 & $10(23.8)$ & 3.6 & \\
\hline DDH & 33 & $1(3.0)$ & 0.3 & \\
\hline BH & 9 & $2(22.2)$ & 0.69 & \\
\hline Total & 289 & $24(8.5)$ & 9 & \\
\hline
\end{tabular}

Table 4. Occupation wise distribution of positive DV cases

\begin{tabular}{lccc}
\hline $\begin{array}{l}\text { Occupation } \\
\text { group }\end{array}$ & $\begin{array}{c}\text { Total } \\
\text { number } \\
\text { of } \\
\text { samples }\end{array}$ & $\begin{array}{c}\text { Number of } \\
\text { Positive } \\
\text { samples (\%) }\end{array}$ & $\begin{array}{c}\% \text { of } \\
\text { positive } \\
\text { cases in } \\
\text { total }\end{array}$ \\
\hline Agriculture & 55 & $7(12.7)$ & 19 \\
\hline Labour & 13 & $1(7.7)$ & 4.5 \\
\hline Job holder & 11 & $0(0.0)$ & 3.8 \\
\hline Business & 15 & $2(13.3)$ & 5.2 \\
\hline Student & 104 & $11(10.6)$ & 36 \\
\hline House wife & 70 & $5(7.1)$ & 24.2 \\
\hline Others & 21 & $0(0.0)$ & 7.3 \\
\hline Total & 289 & $26(8.99)$ & \\
\hline Statistics $\left(\chi^{2}=5.438 ; \mathrm{p}=0.48\right)$ & & \\
\hline
\end{tabular}


ce with some of the previous findings from Nepal studies. $11,12,13$ The present study result shows less positivity rate than the above reports which could be due to variation in geographical distribution. The growth of population and urbanization, increased rate of deforestation, change in environment condition may contribute to the increase in the prevalence of the disease .The increased rate of migration due to open border might also be the predisposing factor as Terai belt of Nepal is bordered with India. However, the result was in harmony to the other study in Nepal. ${ }^{14}$

Out of 26 positive cases obtained in this study, 16 were male patients who constitute $10.8 \%$ of the total male cases and 10 were female patients which comprise $7.1 \%$ of the total female cases. Statistically there was no significant relationship between sex and the occurrence of disease ( $p=$ 0.04 ). The ratio of dengue positive cases in male to female was found to be 1.5:1. In present study the numbers of cases were more in males because males are more likely to be exposed to mosquitoes during their outdoor activities. The result is in agreement with Ministry of Health, Bangladesh that reported hospital patients with DF having male to female ratio of 1.5:1 during an outbreak in Chittangong in 1997.

The age wise distribution of positive dengue cases were highest in the age group below 15 years i.e. pediatric age group $10(12.3 \%)$ followed by age group above 50 years which accounted 3 (8.3\%) and $15-50$ years comprising 13 (7.5\%). Statistically, there is no significant relationship between age groups for the occurrence of disease $(\mathrm{p}=0.24)$. The reason for the higher number positive cases in the child age group might be due to they have less developed immune system. The result is in hormony with the data obtained in outbreak of dengue in Nepal in the year 2006 in which dengue positives cases were recorded in age group greater than 15 years ${ }^{9}$

Out of five hospitals, the highest number of dengue positive cases 10 (23.8\%) were from Tanahu District Hospital, Damouli followed by Bharatapur Hospital,Chitwan (2 cases, 22.2), Koshi Zonal Hospital, Biratnagar (4 cases, $12.5 \%$ ) and Narayani Sub-regional Hospital, Birganj ( 9 cases, $5.2 \%$ ) and least number of cases (1 cases, $3.0 \%$ ) in Dhading District Hospital, Dhading Besi. Out of 26 positive cases, Tanahu District Hospital recorded the highest number of positive cases. The comparatively higher positive cases in Damouli might be due to travel to endemic region as one of the positive case from Tanahu had travel history to Chitwan or wide viral circulation. Besides, Tanahu is bordered with Chitwan, one of the dengue outbreak district of 2010 epidemic in Nepal. Tanahu also consists of a lots of marshy places which provide excellent mosquito breeding places. The prevalence among patients from Narayani Sub-regional Hospital in this study was not in accordance with other findings at that hospital. ${ }^{12}$ This might be due to decrease in vector population or awareness among population in that region.

The Occupation group, business (13.3\%) was found most affected followed by agriculture (11.5\%), student (9.9\%), labour (7.6\%), house wife (7.3\%) and least in job holder and others (0\%). Statistically, there is no significant difference in occurrence of the disease among different occupations $(p=0.637)$. The higher positivity in occupation group business might be due to businessman frequently involved in travel from one place to other and in outdoor activities and there may be chance of being bitten by mosquitoes like $A$. aegypti. The findings were not in accordance with other findings in Nepalese studies as most of the other Nepalese studies have reported agriculture group as the most affected occupation group. ${ }^{12,14}$

\section{CONCLUSION}

In 2010, total 289 samples collected and tested from five different hospitals of Nepal and 26 were found to be positive for DVI. Dengue was detected in Damouli, Biratnagar, Birgunj, Dhading Besi and Chitwan. The samples tested for anti-dengue IgM antibody by ELISA and the IgM positivity was $9 \%$. The sero-prevalence of dengue has marginally increased from terai to hilly region so the concerned authority should initiate extensive surveillance of dengue virus infection and commence an integrated vector control programme in order to abate from a panic viral disease.

IgM capture ELISA was used for laboratory analysis and remains as a reliable and inexpensive method for the diagnosis of dengue. Hence, the IgM capture ELISA has become the most accepted technique for the diagnosis of dengue in developing countries like Nepal.

\section{ACKNOWLEDGEMENT}

We thank to Nepal Academy of Science and Technology for Financial support for ELISA Kits and reagents as well as technical assistance. We would like to thanks Dr. Durga Datt Joshi for providing laboratory facilities and all staff of Everest International Clinic and Research Centre for their technical support. All participating hospitals staffs during the research work. 
CONFLICT OF INTEREST: None to declare.

FINANCIAL INTEREST: None to declare.

\section{REFERENCES}

1. Gubler DJ. Dengue and dengue hemorrhagic fever. Clin Microbiol Rev 1998;11:480-496.

2. Gibbons RV, Vaughn DW. Dengue: an escalating problem. BMJ 2002;324:1563-1566.

3. Rothman AL. Dengue: defining protective versus pathologic immunity. J Clin Invest 2004; 113: 946-951.

4. World Health Organization. Dengue guidelines for diagnosis, treatment, prevention and control-WHO; 2009.

5. Epidemiology and Disease Control Division (EDCD). Department of Health Services (DoHS), Ministry of Health, Government of Nepal. Annual report 2006/2007.

6. Pandey B, Rai S, Morita K. First case of dengue in Nepal. J Nepal Med Coll 2004;6:157-159

7. Pandey B, Morita K, Khanal S. Dengue virus, Nepal. Emerg Infect Dis 2008;14:514-515.

8. Takasaki T, Kotaki A, Nishimura K. Dengue virus type 2 isolated from an imported dengue patient in Japan: first isolation of dengue virus from Nepal. J Travel Med 2008;15:46-49.

9. World Health Organization. Outbreak investigation of DF in Nepal. New Delhi; WHO Regional Office for Southeast Asia; 2006.

10. Pandey B, Yamamoto A, Morita K. Serodiagnosis of japanese encephalitis among Nepalese patients by the particle agglutination assay. Epidemiol Infect 2003;131: 881-885.

11. Pun R. Sero-epidemiology of dengue virus in post monsoon period in terai region of Nepal. M. Sc. Dissertation submitted to Central Department of Microbiology, Tribhuvan University, Kathmandu, Nepal 2009.

12. Sah 0. Serological study of dengue virus infection in terai region, Nepal. M.Sc. Dissertation submitted to Department of Microbiology, National College, Kathmandu, Nepal 2008.

13. Sherchand J, Pandey B, Haruki K. Sero-diagnosis of Japanese encephalitis and dengue virus infection from clinically suspected patients of Nepal. J Inst. Med 2001; 23: 81-85.

14. Shah Y. Sero-epidemiology of Dengue Virus infection in Western terai region of Nepal. M. Sc. Dissertation submitted to Department of Microbiology, Kathmandu College of Science and Technology, Kathmandu, Nepal 2010.

\section{Citing this article}

Shah Y, Khadka G, Gupta GP, Adhikari N, Poudel A, Pant KP, Dahal B, Pandey BD. Sero-diagnosis of Dengue virus in Different Hospitals of Nepal. Int J Infect Microbiol 2012;1(2);58-62. 